\title{
Time and Fuel Optimal Power Response of a Diesel-Electric Powertrain
}

\author{
Martin Sivertsson* Lars Eriksson* \\ * Vehicular Systems, Dept. of Electrical Engineering, Linköping \\ University, SE-58183 Linköping, Sweden, \{marsi,larer\}@isy.liu.se.
}

\begin{abstract}
Optimal control policies for a diesel-electric powertrain in transient operation are studied. In order to fully utilize the extra degree of freedom available in a diesel-electric powertrain, compared to a conventional powertrain, the engine-speed is allowed to vary freely. The considered transients are steps from idle to target power. A non-linear four state-three input mean value engine model, incorporating the important turbocharger dynamics, is used for this study. The study is conducted for two different criteria, fuel optimal control and time optimal control. The results from the optimization show that the optimal controls for each criteria can be divided into two categories, one for high requested powers and one for low requested powers. For high power transients the controls for both criteria follow a similar structure, a structure given by the maximum torque line and the smoke-limiter. The main difference between the criteria is the end point and how it is approached. The fuel optimal control builds more kinetic energy in the turbocharger, reducing the necessary amount of kinetic energy in the system to produce the requested power. For low power transients the optimal controls deal with the turbocharger dynamics in a fundamentally different way.
\end{abstract}

Keywords: Optimal Control, Diesel-Electric Powertrain

\section{INTRODUCTION}

New legislative demands for emissions and increasing oil prices have renewed the interest for alternative powertrain concepts. One such concept is the diesel-electric powertrain, such as the BAE Systems TorqE ${ }^{\mathrm{TM}}$, see Fig. 1, where there is only an electric link between the diesel engine and the electric load. This adds an extra degree of freedom to the powertrain since the engine speed can be chosen freely. This offers potential for increasing the performance of the powertrain, due to the torque characteristic of the electric machine, as well as potential reduction in consumption, due to the freedom of choosing the operating point of the diesel engine. The absence of an energy storage makes the system more restricted and difficult to manage, compared to a hybrid.

This paper studies how to best take advantage of the extra freedom available in the diesel-electric powertrain. In related articles concerning optimal transient control of diesel-engines different optimization methods are used to minimize pollutants during transient operation for known engine speeds, see Benz et al. (2011); Kyrtatos et al. (2003) or, as in Nilsson et al. $(2011,2012)$ the optimal engine operating point trajectory for a known engine power output trajectory is derived. The diesel engine is modeled as an inertia with a Willans-line efficiency model. The optimal solution is found using dynamic programming and Pontryagins maximum principle. Due to the more detailed and complex non-linear model used in this paper such methods aren't feasible. The problem is solved using the ACADO Toolkit, an open-source framework for automatic control and dynamic optimization, that uses multiple

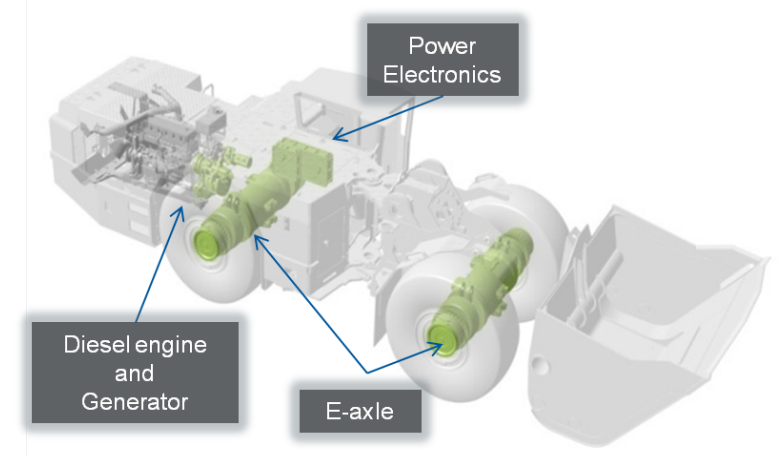

Fig. 1. BAE Systems TorqE $\mathrm{E}^{\mathrm{TM}}$ powertrain

shooting together with sequential quadratic programming, see Houska et al. (2011).

The contribution of this paper is the study of the optimal control from idle to a target power for two different criteria with the engine output power and engine speed considered free variables during the transient. A nonlinear, four state, three input mean value engine model (MVEM) is used in the study and provided, fully parametrized, in this paper. This MVEM incorporates the important turbocharger dynamics as well as the nonlinear multiple input-multiple output nature of the diesel engine. The model is also continuous in the studied interval in compliance with the non-linear program solver of the ACADO Toolkit. 


\section{MODEL}

The focus in the paper lies on optimal control of diesel engine transients. Therefore the generator model is simplified, i.e. the generator efficiency is constant and the maximum power of the generator is constant over the entire speed range. The generator time constant is also assumed to be much faster than the time constant of the engine.

The modeled engine is a 6-cylinder 12.7-liter SCANIA diesel engine with a fixed-geometry turbine and a wastegate for boost control. The states of the MVEM are engine speed, $\omega_{i c e}$, inlet manifold pressure, $p_{i m}$, exhaust manifold pressure, $p_{e m}$, and turbocharger speed, $\omega_{t c}$ and the controls are fuel flow, $u_{f}$, wastegate position, $u_{w g}$, and generator power, $P_{g e n}$. The MVEM consists of two control volumes, intake and exhaust manifold, and four restrictions, compressor, engine, turbine, and wastegate. The control volumes are modeled with the standard isothermal model, using the ideal gas law and mass conservation. The engine and turbocharger speeds are modeled using Newton's second law. The governing differential equations of the MVEM are:

$$
\begin{aligned}
\frac{d \omega_{i c e}}{d t} & =\frac{1}{J_{g e n s e t}}\left(T_{i c e}-\frac{P_{g e n}}{\omega_{i c e}}\right) \\
\frac{d p_{i m}}{d t} & =\frac{R_{a} T_{i m}}{V_{i s}}\left(\dot{m}_{c}-\dot{m}_{a c}\right) \\
\frac{d p_{e m}}{d t} & =\frac{R_{e} T_{e m}}{V_{e m}}\left(\dot{m}_{a c}+\dot{m}_{f}-\dot{m}_{t}-\dot{m}_{w g}\right) \\
\frac{d \omega_{t c}}{d t} & =\frac{P_{t}-P_{c}}{\omega_{t c} J_{t c}}-w_{f r i c} \omega_{t c}^{2}
\end{aligned}
$$

For more in-depth information on the structure and details of the diesel engine model see Eriksson (2007); Wahlström and Eriksson (2011), from where the equations in the following section are collected. Descriptions and the parameters and constants used in the engine model can be found in Appendix A. The model has been adapted to ensure that there are continuous derivatives.

\section{COMPONENT MODELS}

\subsection{Compressor}

The compressor model consists of two sub-models, one for the massflow and one for the power consumption. In order to avoid problems for low turbocharger speeds and transients with pressure ratios $\Pi_{c}<1$ a variation of the physically motivated $\Psi \Phi$ model in Eriksson (2007) is used.

$$
\begin{aligned}
\Pi_{c, \text { max }} & =\left(\frac{\omega_{t c}^{2} R_{c}^{2} \Psi_{\max }}{2 c_{p} T_{a m b}}+1\right)^{\frac{\gamma_{a}}{\gamma_{a}-1}} \\
\dot{m}_{c, \text { corr }} & =\dot{m}_{c, \text { corr }, \max } \sqrt{1-\left(\frac{\Pi_{c}}{\Pi_{c, \text { max }}}\right)^{2}} \\
\dot{m}_{c} & =\frac{\dot{m}_{c, \text { corr }} p_{a m b} / p_{r e f}}{\sqrt{T_{a m b} / T_{r e f}}} \\
P_{c} & =\frac{\dot{m}_{c} c_{p a} T_{a m b}\left(\Pi_{c}^{\frac{\gamma a-1}{\gamma a}}-1\right)}{\eta_{c}}
\end{aligned}
$$

The full compressor model has three tuning parameters $\Psi_{\max }, \dot{m}_{c, \text { corr }, \max }$, and $\eta_{c}$.

\subsection{Engine Gas Flow}

The engine gas flow model consist of two sub-models, one for air flow and on for fuel flow.

$$
\begin{aligned}
\dot{m}_{a c} & =\frac{\eta_{v o l} p_{i m} \omega_{i c e} V_{D}}{4 \pi R_{a} T_{i m}} \\
\dot{m}_{f} & =\frac{10^{-6}}{4 \pi} u_{f} \omega_{i c e} n_{c y l} \\
\lambda & =\frac{\dot{m}_{a c}}{\dot{m}_{f}} \frac{1}{(A / F)_{s}}
\end{aligned}
$$

To avoid problems for $\dot{m}_{f}=0$ a new variable is defined

$$
\phi_{\lambda}=\dot{m}_{a c}-\lambda_{m i n} \dot{m}_{f}(A / F)_{s}
$$

where $\lambda_{\min }$ is the lower limit set by the smoke-limiter. The gas flow model has one tuning parameter, $\eta_{v o l}$.

\subsection{Engine Torque}

The net torque of the engine, $T_{i c e}$, is modeled using three torque components, and one efficiency model.

$$
\begin{aligned}
T_{i c e} & =T_{i g}-T_{\text {fric }}-T_{\text {pump }} \\
\eta_{i g} & =\eta_{i g, c h}\left(1-\frac{1}{r_{c}^{\gamma_{c y l}-1}}\right) \\
T_{i g} & =\frac{u_{f} 10^{-6} n_{c y l} q_{H V} \eta_{i g}}{4 \pi} \\
T_{f r i c} & =\frac{V_{D}}{4 \pi} 10^{5}\left(c_{f r 1} \omega_{i c e}^{2}+c_{f r 2} \omega_{i c e}+c_{f r 3}\right) \\
T_{\text {pump }} & =\frac{V_{D}}{4 \pi}\left(p_{\text {em }}-p_{i m}\right)
\end{aligned}
$$

The net torque, $T_{i c e}$ is limited by the maximum torque of the engine, $T_{i c e, \max }\left(\omega_{i c e}\right)$, shown in Fig. 3 . The torque model has five tuning parameters, $\eta_{v o l}, c_{f r, i}, i \in[1,2,3]$, and $\eta_{i g, c h}$.

\subsection{Exhaust Temperature}

The engine out temperature model is based on ideal gas Seliger cycle. The temperature drop in the exhaust manifold is not modeled so the engine out temperature and exhaust manifold temperature are assumed to be equal.

$$
\begin{aligned}
q_{i n}= & \frac{\dot{m}_{f} q_{H V}}{\dot{m}_{f}+\dot{m}_{a c}} \\
x_{p}= & 1+\frac{q_{i n} x_{c v}}{c_{v a} T_{i m} r_{c}^{\gamma_{a}-1}} \\
T_{e m}= & \eta_{s c} \Pi_{e}^{1-1 / \gamma_{a}} r_{c}^{1-\gamma_{a}} x_{p}^{1 / \gamma_{a}-1} \\
& \left(q_{i n}\left(\frac{1-x_{c v}}{c_{p a}}+\frac{x_{c v}}{c_{v a}}\right)+T_{i m} r_{c}^{\gamma_{a}-1}\right)
\end{aligned}
$$

The engine out temperature model has two tuning parameters $\eta_{s c}$, and $x_{c v}$.

\subsection{Turbine}

The turbine model consists of submodels for the turbine massflow and turbine power production. The turbine massflow model is modeled with the standard restriction model and using that half the expansion occurs in the rotor and the other half in the stator, see Eriksson (2007):

$$
\Pi_{t}^{*}=\max \left(\sqrt{\Pi_{t}},\left(\frac{2}{\gamma_{e}+1}\right)^{\frac{\gamma_{e}}{\gamma_{e}-1}}\right)
$$




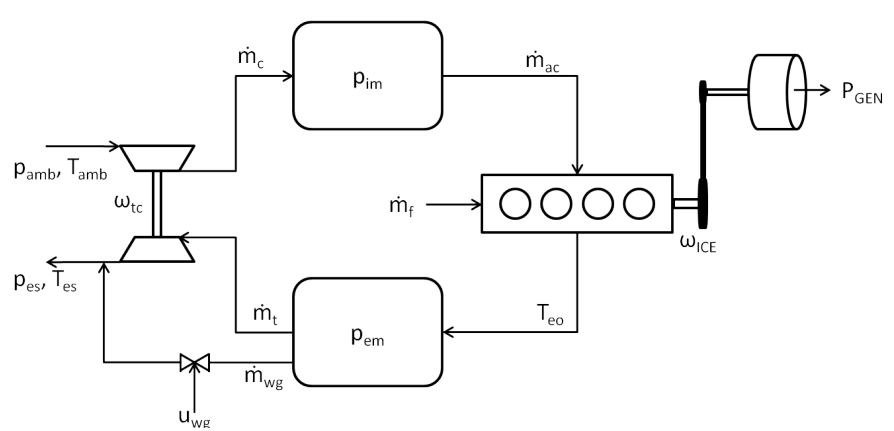

Fig. 2. Structure of the MVEM. The modeled components as well as the connection between them.

The ACADO Toolkit requires that the functions are continuous and therefore $\Pi_{t}^{*}=\sqrt{\Pi_{t}}$ is used which is valid down to $\Pi_{t}=0.30$ corresponding to an exhaust manifold pressure of $p_{e m} \approx 3.3 p_{a m b}$, which is sufficient for the transients studied. The massflow model is then given by:

$$
\begin{aligned}
\Pi_{t}^{*} & =\sqrt{\Pi_{t}} \\
\Psi_{t}\left(\Pi_{t}^{*}\right) & =\sqrt{\frac{2 \gamma_{e}}{\gamma_{e}-1}\left(\left(\Pi_{t}^{*}\right)^{\frac{2}{\gamma_{e}}}-\left(\Pi_{t}^{*}\right)^{\frac{\gamma_{e}+1}{\gamma_{e}}}\right)} \\
\dot{m}_{t} & =\frac{p_{e m}}{\sqrt{R_{e} T_{e m}}} \Psi_{t} A_{t, e f f} \\
P_{t} & =\dot{m}_{t} c_{p e} T_{e m} \eta_{t}\left(1-\Pi_{t}^{\frac{\gamma_{e}-1}{\gamma_{e}}}\right)
\end{aligned}
$$

The tuning parameters of the complete turbine model are $A_{t, e f f}$, and $\eta_{t}$.

\subsection{Wastegate}

If the standard restriction model is applied to the wastegate, choking would occur for exhaust manifold pressures of $p_{e m} \approx 1.8 p_{a m b}$ which is well within the normal operating region. This requires a discontinuity in the model, but since ACADO Toolkit requires the functions to be continuous the following non-physical model is used instead:

$$
\begin{aligned}
\Psi_{w g} & =c_{w g, 1} \sqrt{1-\Pi_{w g}^{c_{w g, 2}}} \\
\dot{m}_{w g} & =\frac{p_{e m}}{\sqrt{R_{e} T_{e m}}} \Psi_{w g} u_{w g} A_{w g, e f f}
\end{aligned}
$$

The tuning parameters of the wastegate model are $c_{w g, 1-2}$ and $A_{\text {wg,eff }}$.

\section{PROBLEM FORMULATION}

Two non-linear optimal control problems, minimum time and minimum energy are studied. They are formulated as follows:

$$
\begin{array}{cl}
\min & \int_{0}^{T} \dot{m}_{f} \mathrm{dt} \quad \text { or } \quad \min T \\
\text { s.t. } & \dot{x}=f(x, u),
\end{array}
$$

where $x$ is the states of the MVEM and $\dot{x}$ is defined by (1)(4). The studied transients are steps from idle to a target power subject to constraints imposed by the components, such as maximum torque and minimum speed, as well as environmental constraints, i.e. a limit on $\phi_{\lambda}$ set by the smoke-limiter. The constraints are:

$$
\begin{array}{ll}
x(0)=\text { idle }, & \dot{x}(T)=0 \\
T_{i c e} \leq T_{i c e, \max }\left(\omega_{i c e}\right), & P_{\text {gen }}(T)=P_{\text {req }} \\
\omega_{\text {ice }} \geq \omega_{\text {ice } \min }, & \phi_{\lambda} \geq 0
\end{array}
$$

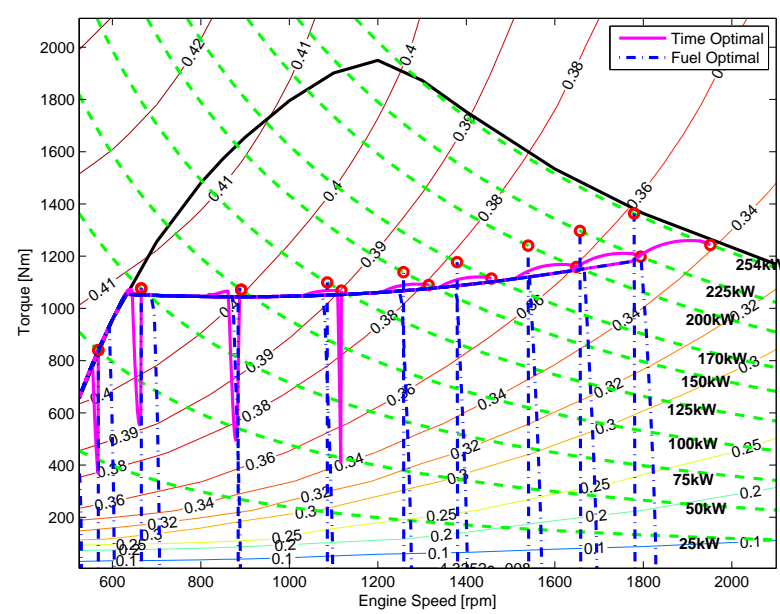

Fig. 3. Time and fuel optimal solutions to different load transients. The time and fuel optimal transients have similar structures, given by the smoke-limiter, but differ in how they meet the end constraints.

In most vehicles the accelerator position can be interpreted as a power request. The problem in (28)-(29) is thus how to control the engine in order to be able to satisfy the operators power request, either as fast as possible, or as fuel efficient as possible. The end constraint on the state derivatives is to avoid solutions where the optimal control ends in an operating point that cannot be maintained. This is to avoid under- or overshoots in the control strategies. Not specifying that $\dot{\omega}_{i c e}(T) \geq 0$ will lead to the engine transient not taking place at all, the optimal solution is just to apply $P_{\text {gen }}=P_{\text {req }}$ at $t=0$.

However, one could argue that the strict equality in the derivative end constraint should be replaced by an inequality, $\dot{x}(T) \geq 0$ since this would ensure that the engine can deliver at least the power requested. Therefore effects of relaxing these constraints are also studied.

\section{RESULTS}

The optimal torque and speed trajectories to problem (28)(29) are shown in Fig. 3 and the corresponding end time $\mathrm{T}$ as well as the fuel consumption and end state values are shown in Table 1. One observation that can be made is that the optimal solutions can be divided into two cases. One case where the time optimal and fuel optimal paths end in the same operating point $\left(P_{r e q} \leq 100 \mathrm{~kW}\right)$, discussed in Section 7 , and one case where they don't $\left(P_{r e q} \geq 125 \mathrm{~kW}\right)$, discussed in Section 6.

\section{TRANSIENTS TO HIGH POWER}

The time and fuel optimal control trajectories for $P_{r e q} \geq$ $125 \mathrm{~kW}$ all follow the same pattern as the transients shown in Fig. 4 where $P_{r e q}=170 \mathrm{~kW}$. The time optimal and fuel optimal control strategies are rather similar for the first phase of the transient, the difference lies in how they approach the stationary point. The optimal solution for both criteria is to put as much energy as possible into the system in order to build intake manifold pressure and turbo speed, the difference lies in the fine tuning to meet the end constraints. This becomes even more apparent 
Table 1. Optimal results for different load transients.

\begin{tabular}{cccccccc}
\hline \hline$P_{\text {req }}(T)$ & $\min$ & $\mathrm{T}[\mathrm{s}]$ & $m_{f}[\mathrm{~g}]$ & $\omega_{i c e}(T)$ & $p_{i m}(T)$ & $p_{\text {em }}(T)$ & $\omega_{t c}(T)$ \\
\hline \multirow{2}{*}{$25 \mathrm{~kW}$} & $T$ & 0.053 & 0.108 & 54.31 & 101505 & 102270 & 799.2 \\
& $m_{f}$ & 0.192 & 0.018 & 54.00 & 101502 & 102259 & 795.4 \\
\hline \multirow{2}{*}{$50 \mathrm{~kW}$} & $T$ & 0.083 & 0.246 & 59.53 & 101996 & 103035 & 1022.6 \\
& $m_{f}$ & 0.348 & 0.112 & 59.53 & 101996 & 103035 & 1022.6 \\
\hline \multirow{2}{*}{$75 \mathrm{~kW}$} & $T$ & 0.115 & 0.417 & 69.68 & 102763 & 104229 & 1316.6 \\
& $m_{f}$ & 0.395 & 0.267 & 69.68 & 102763 & 104229 & 1316.6 \\
\hline \multirow{2}{*}{$100 \mathrm{~kW}$} & $T$ & 0.165 & 0.706 & 93.32 & 104207 & 106927 & 1798.8 \\
& $m_{f}$ & 0.174 & 0.601 & 93.32 & 104207 & 106927 & 1798.8 \\
\hline \multirow{2}{*}{$125 \mathrm{~kW}$} & $T$ & 0.219 & 1.114 & 117.06 & 106682 & 111284 & 2377.3 \\
& $m_{f}$ & 0.265 & 1.077 & 113.68 & 109167 & 114059 & 2686.1 \\
\hline \multirow{2}{*}{$150 \mathrm{~kW}$} & $T$ & 0.286 & 1.689 & 137.67 & 111918 & 119322 & 3177.8 \\
& $m_{f}$ & 0.333 & 1.592 & 131.73 & 115468 & 122916 & 3494.4 \\
\hline \multirow{2}{*}{$170 \mathrm{~kW}$} & $T$ & 0.334 & 2.176 & 152.54 & 117012 & 127112 & 3797.0 \\
& $m_{f}$ & 0.380 & 2.018 & 144.43 & 121248 & 131128 & 4097.4 \\
\hline \multirow{2}{*}{$200 \mathrm{~kW}$} & $T$ & 0.397 & 2.936 & 172.63 & 125505 & 140527 & 4672.0 \\
& $m_{f}$ & 0.440 & 2.665 & 161.22 & 130550 & 144850 & 4930.1 \\
\hline \multirow{2}{*}{$225 \mathrm{~kW}$} & $T$ & 0.443 & 3.595 & 187.85 & 133008 & 153052 & 5365.8 \\
& $m_{f}$ & 0.485 & 3.212 & 173.50 & 138638 & 157391 & 5578.3 \\
\hline \multirow{2}{*}{$254 \mathrm{~kW}$} & $T$ & 0.491 & 4.397 & 204.36 & 141931 & 169007 & 6160.3 \\
& $m_{f}$ & 0.534 & 3.864 & 186.30 & 148172 & 173036 & 6301.3 \\
\hline
\end{tabular}
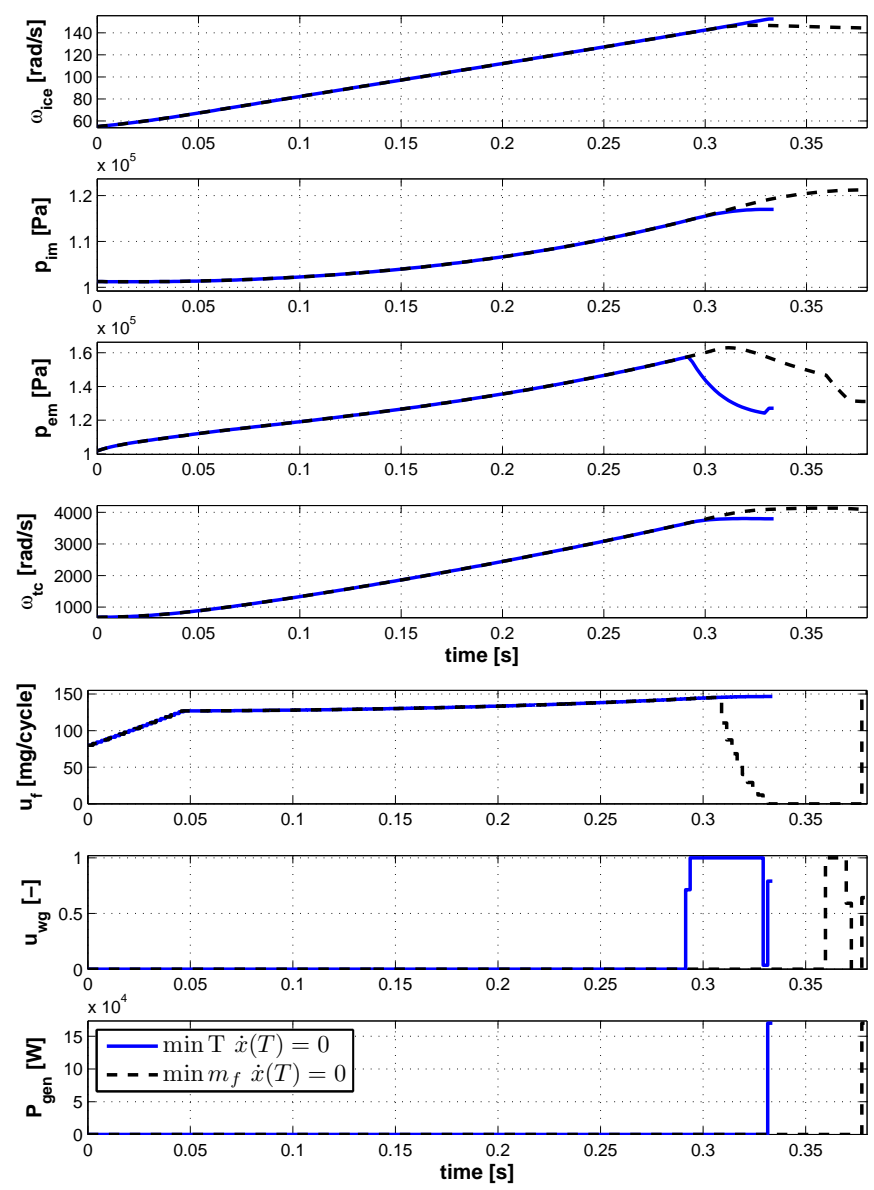

Fig. 4. Time and fuel optimal solutions to a load transient from idle to $170 \mathrm{~kW}$.

when looking at Fig. 3, where both fuel and time optimal torque-engine speed paths for different required powers are shown.

\subsection{Time optimal high power transients}

The time optimal solution approaches the stationary point from a higher torque, whereas the fuel optimal solution approaches the stationary point from a lower torque. In the first phase the optimal solution follows the maximum torque and the $\lambda_{m i n}$-value set by the smoke-limiter of the engine. The time optimal solution follows $\lambda_{\min }$ until the end and actuates the wastegate to get stationarity. When the wastegate is actuated to control the turbocharger speed to its target speed the pumping work decreases and the net torque of the engine increases and the path thus approaches the end point from a higher torque.

\subsection{Fuel optimal high power transients}

The fuel optimal solution approaches a different stationary point, one that has a higher $p_{i m}, p_{e m}$, and $\omega_{t c}$ but lower $\omega_{i c e}$, and consequently higher efficiency. This stationary point is near the operating point with maximum efficiency obtainable without using the generator to restrain the engine speed from increasing as it builds turbocharger speed. In Fig. 5 it is shown how much energy is stored as kinetic energy in the turbocharger and engine at the end of the transient. The fuel optimal control builds less kinetic energy in the engine, but more kinetic energy in the turbocharger than the time optimal control. This reduces the total amount of kinetic energy necessary to be able to meet $P_{r e q}$. This energy difference scaled with the average efficiency of the engine is roughly of the same size as the difference in consumption between the criteria shown in Table 1. Seeing that the kinetic energy in the engine is roughly 20 times larger than that in the turbocharger a lot can be gained by instead increasing the kinetic energy in the turbocharger and thus decrease the kinetic energy in the engine. The time constant of the turbocharger is however larger than that of the engine. When limited by the smoke-limiter, the kinetic energy in the turbocharger increases with roughly $10 \mathrm{~kJ} / \mathrm{s}$, whereas the kinetic energy of the engine increases with $100 \mathrm{~kJ} / \mathrm{s}$, causing the two criteria to approach different stationary points.

The difference in control of the turbocharger dynamics can be seen in Fig.4, $t \in[0.28,0.4]$. Where the time optimal control follows the smoke-limiter until the end and fully opens the wastegate to release the excess exhaust pressure as it approaches its stationary point, the fuel optimal control decreases and stops the fuel injection while the wastegate remains closed in order to build/maintain backpressure to convert to turbocharger speed and consequently intake manifold pressure. The transient ends with the wastegate being actuated to control the exhaust manifold pressure to ensure stationarity in $p_{e m}, \omega_{t c}$ and $p_{i m}$ together with the final value of $u_{f}$.

In Fig. 6 the change in end time and fuel consumption as a function of $P_{r e q}$ for the fuel optimal versus the time optimal transients is shown. In the studied interval the consumption decrease of the fuel optimal solution, compared to the time optimal solution, increases with $P_{r e q}$ and is between $3 \%$ and $12 \%$. The corresponding time increase however decreases with $P_{r e q}$ and is between $21 \%$ and $9 \%$.

\subsection{End constraint effects on the optimal solution}

In order to understand why the optimal control takes on the form seen in Fig. 4 the optimization procedure is repeated for different end constraints. Looking at Fig. 7 

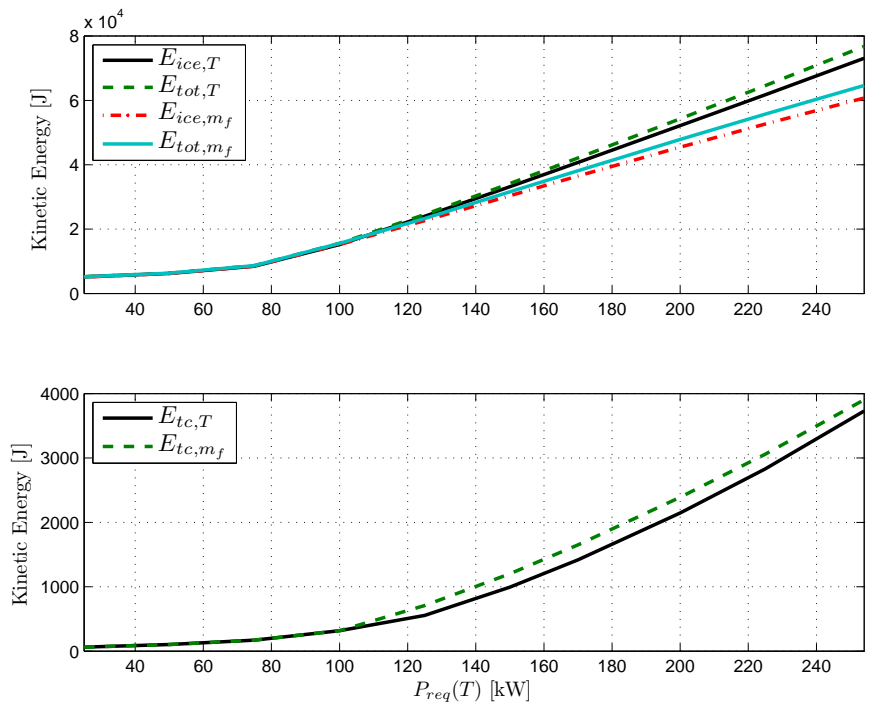

Fig. 5. Top: Kinetic energy in the engine as well as the total kinetic energy in the system at time $T$. Bottom: Kinetic energy in the turbocharger at time $T$.

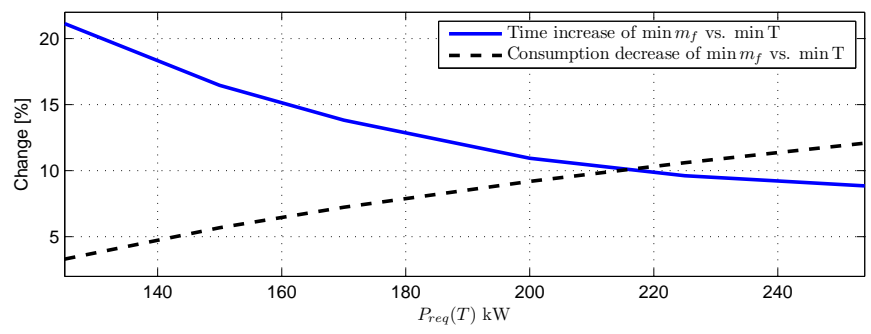

Fig. 6. Change in time and consumption as a function of $P_{\text {req. }}$.

where the time and fuel optimal solutions with the end constraint $\dot{x}(T)=0$ are compared with the solutions for $\dot{\omega}_{i c e}(T)=0$ it's apparent that the control strategies for $u_{f}$ and $P_{\text {gen }}$ are governed by the end constraint on the engine speed derivative. Imposing hard end constraints on the other state derivatives only shifts the control in time. The wastegate actuation however cannot be explained by just that constraint. In Fig. 8 it is shown how the wastegate actuation changes for different end constraints. The end constraints are removed one by one to study how the solution changes. The different end constraints are:

$$
\begin{array}{lll}
\text { Case A: } \dot{\omega}_{i c e}(T)=0, & \dot{p}_{i m}(T)=0, & \dot{p}_{\text {em }}(T)=0 \\
\text { Case B: } \dot{\omega}_{i c e}(T)=0, & \dot{p}_{i m}(T)=0, & \dot{\omega}_{t c}(T)=0 \\
\text { Case C: } \dot{\omega}_{i c e}(T)=0, & \dot{p}_{\text {em }}(T)=0, & \dot{\omega}_{t c}(T)=0
\end{array}
$$

From there the conclusion can be drawn that the opening and closing of the wastegate is to bring the turbocharger speed, and thus also the intake pressure, to its target stationary value. Then the wastegate opens again in the final time-step to get stationarity in the exhaust manifold pressure as well.

\subsection{Effects of relaxing the end constraints}

In Fig. 9 the optimal solutions for $\dot{x}(T) \geq 0$ are compared to the optimal solutions for $\dot{x}(T)=0$. The optimal solution stays relatively unaffected, as can be expected the solutions are a bit shorter in time if the end constraints
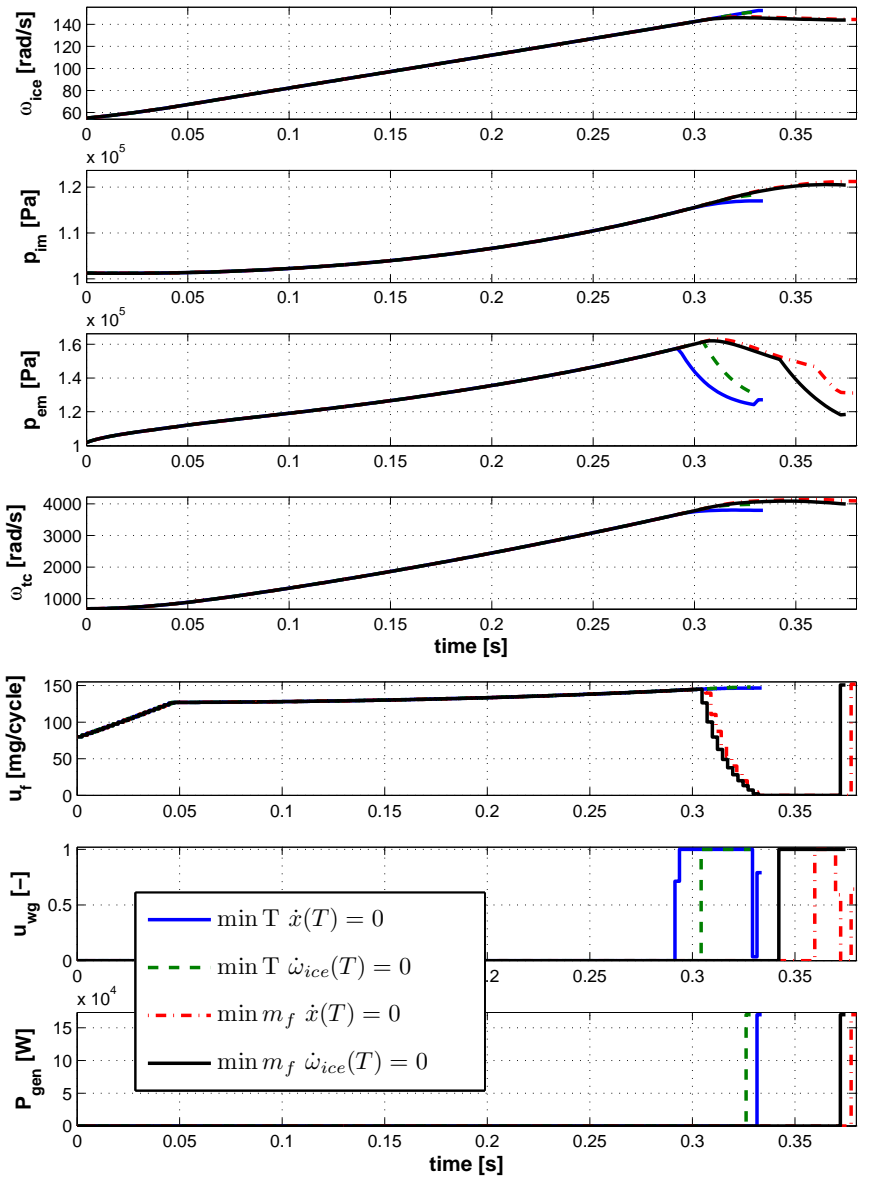

Fig. 7. Time and fuel optimal solutions to a load transient for $\dot{x}(T)=0$ as well as $\dot{\omega}_{i c e}(T)=0$.
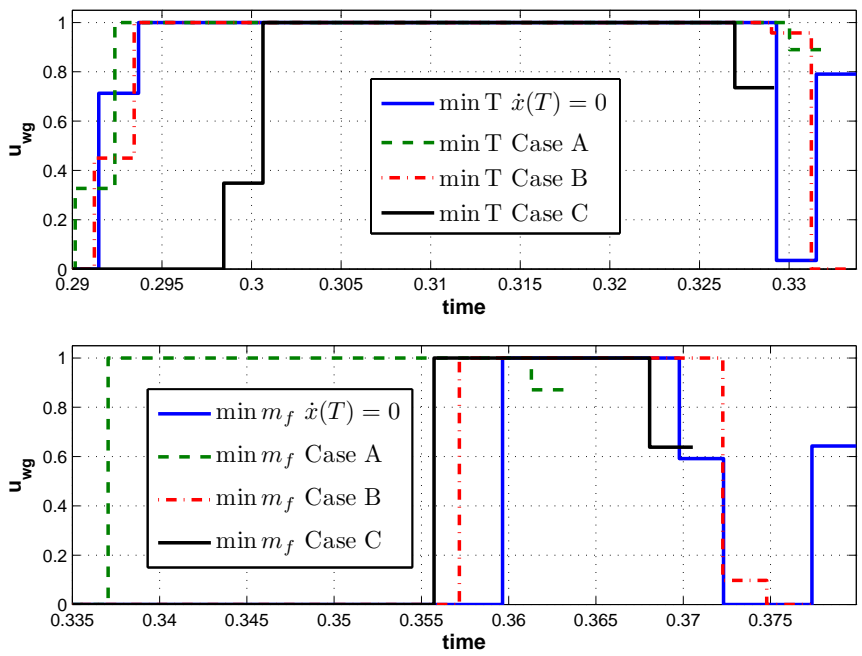

Fig. 8. How the wastegate actuation changes for different end constraints. Top: Time optimal transients. Bottom: Fuel optimal transients.

are relaxed. Worth noting is that the fully open-fully closed actuation of the wastegate disappears. There is also a small difference between the two criterias as to which constraints are active. In the time optimal case only the constraints on $\dot{\omega}_{i c e}$ and $\dot{p}_{e m}$ are active, but in the fuel optimal case all constraints are active except the constraint on $\dot{p}_{i m}$. 

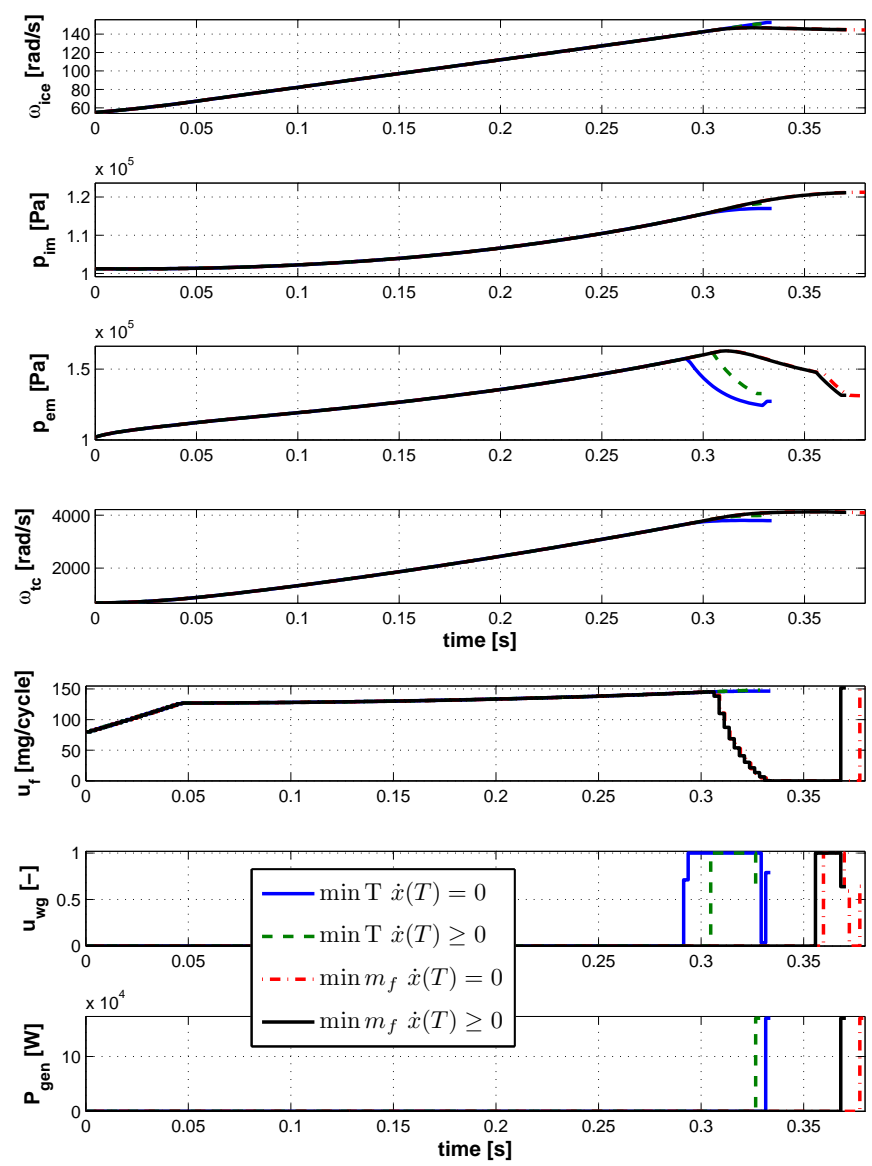

Fig. 9. Effects on the time and fuel optimal solution of relaxing the end constraints.

That is, in the fuel optimal case relaxing the constraints produces the same solution as in Case A.

\section{TRANSIENTS TO LOW POWER}

For low requested powers the optimal control looks a bit different compared to the transients with higher requested powers discussed in Section 6. For the time optimal case this change in strategy occurs for roughly $P_{\text {req }} \leq 100 \mathrm{~kW}$ and in the fuel optimal case around $P_{r e q} \leq 75 \mathrm{~kW}$. Even though, for $P_{r e q} \leq 100 \mathrm{~kW}$, the time and fuel optimal controls end in nearly the same operating point they differ substantially, see Fig. 10.

\subsection{Time optimal transients for low requested powers}

The time optimal control for low powers is to use the generator to decrease the engine speed mid-transient, see Fig. 10. It also ends with departing from the $\lambda_{m i n}$-line as it approaches the same operating point as the fuel optimal solution. The fuel consumption punishment for this is large, up to almost $100 \%$ compared to the fuel optimal solution, see Fig. 11, but the gain in time is also substantial, up to $300 \%$.

\subsection{End constraint impact on the time optimal control}

In order to investigate the nature of the solution the end constraints are removed and relaxed in the same manner
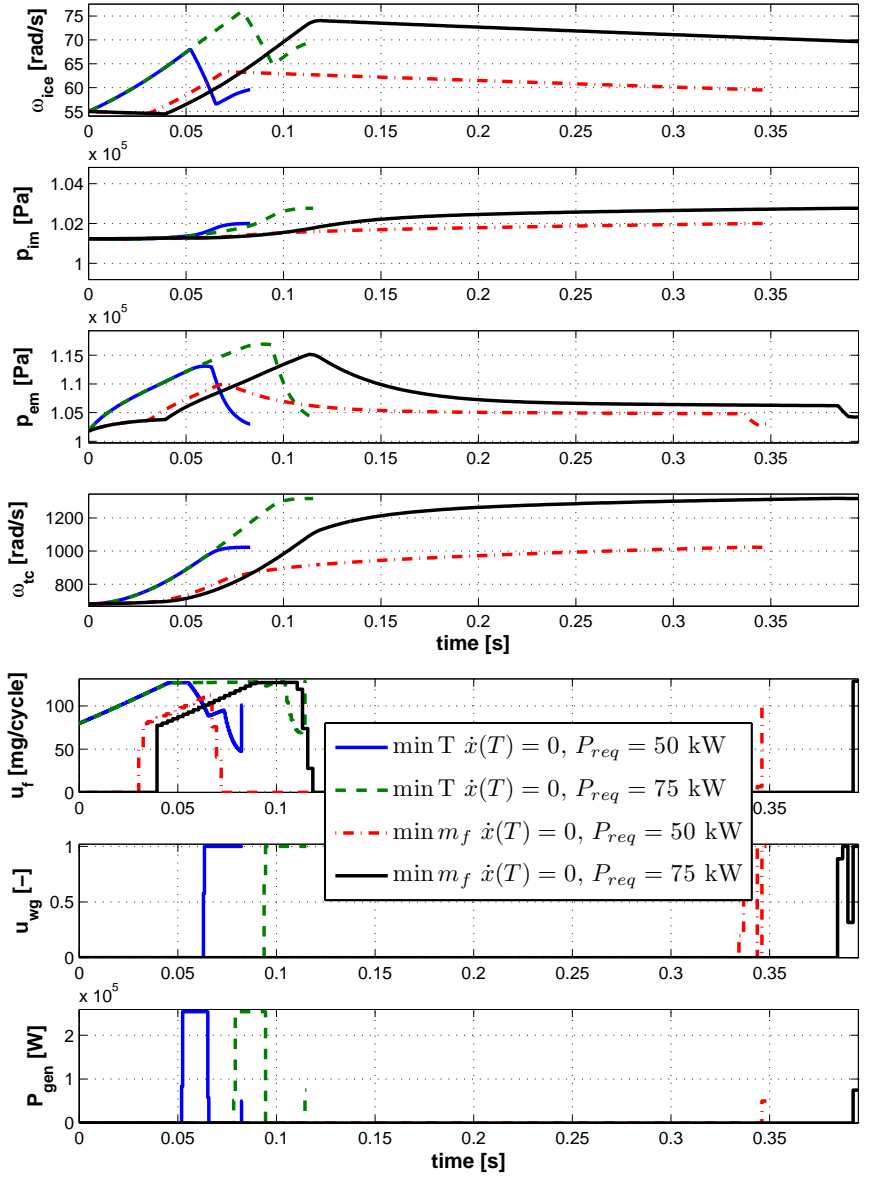

Fig. 10. Time and fuel optimal solutions to a load transient from idle to $50 \mathrm{~kW}$ and $70 \mathrm{~kW}$.

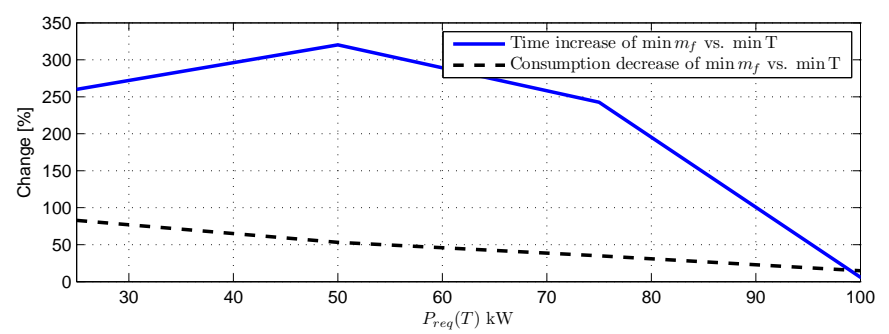

Fig. 11. Change in time and consumption as a function of Preq.

as in Section 6. In this case, as with the fuel optimal solution for higher powers, the optimal solution for Case A is the same as with $\dot{x}(T) \geq 0$. It can be seen in Fig. 12 that the generator control is an artifact of requiring the state derivatives to be zero at the end. If the end constraints are relaxed the solution is of the same structure as for $P_{r e q} \geq 125 \mathrm{~kW}$. Getting the turbocharger speed to a stationary point makes the transient almost 3 times longer, compared to if $\dot{\omega}_{t c}$ is allowed to be positive, the corresponding fuel conusmption also doubles. But since the objective is to minimize the time until the engine can deliver a specified power an eventual over- or undershoot might not be that big of an issue. 

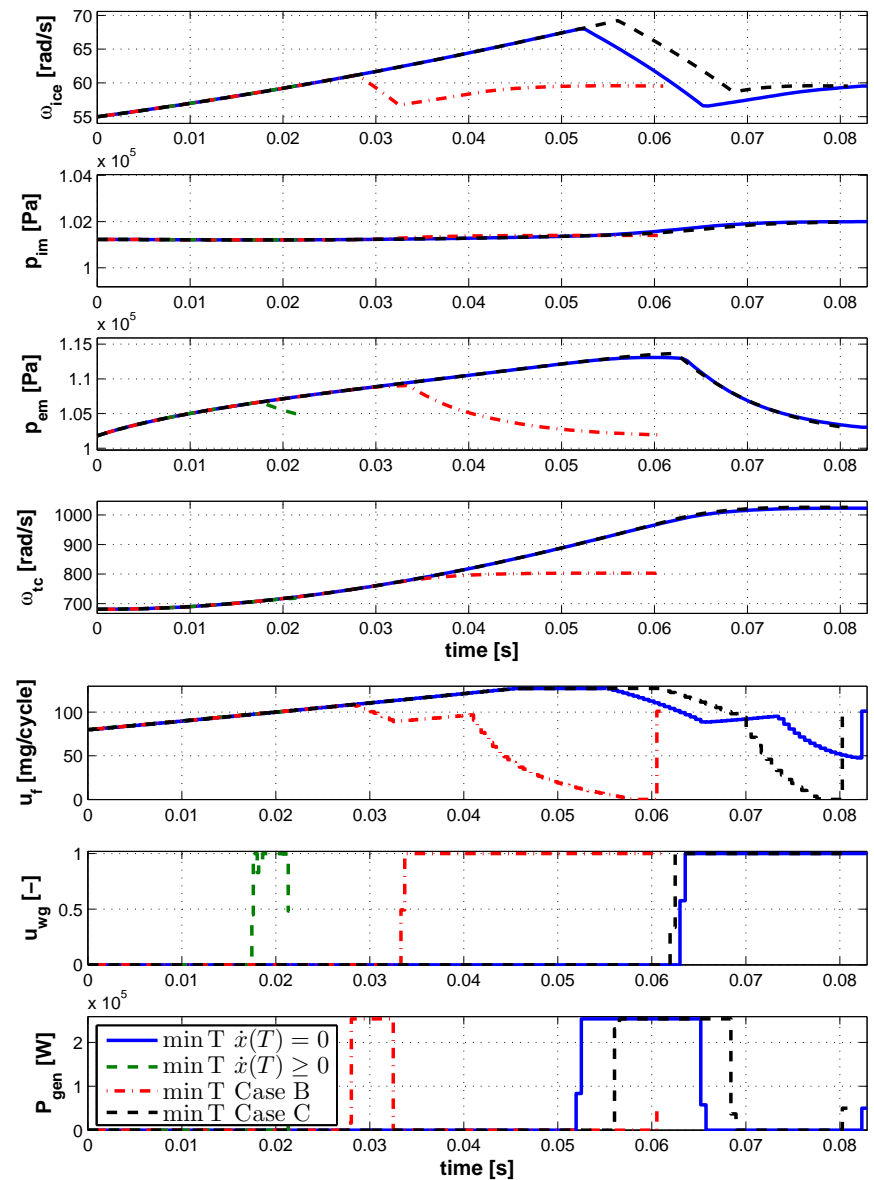

Fig. 12. Time optimal transient and how the solution changes with the end constraints, $P_{r e q}=50 \mathrm{~kW}$.

\subsection{Fuel optimal transients for low requested powers}

The fuel optimal control for low power transients, as seen in see Fig. 10, is first to let the engine decelerate slightly with the wastegate fully closed, building a small amount of exhaust manifold pressure. Then a burst of fuel is injected, adding energy in to the system, before the engine is allowed to decelerate towards its stationary point. During this deceleration the turbocharger speed and inlet manifold pressure continues to build. Interesting to note is that the close-open-close wastegate actuation also appears for low power transients, see Fig. $10 t \in[0.33,0.4]$.

\subsection{End constraint impact on the fuel optimal control}

As was the case for fuel optimal high power transients, as well as time optimal low power transients, Case A and $\dot{x}(T) \geq 0$ produce the same solution. In Fig. 13 the effects of varying the end constraints are shown. The solution for case $\mathrm{C}$ is very close to $\dot{x}(T)=0$, the only difference is at the end, since case $\mathrm{C}$ doesn't require $\dot{p}_{i m}=0$. The end constraints that define the solution the most are thus $\dot{\omega}_{t c}$ and $\dot{p}_{e m}$. Requiring that these constraints should be zero at the end increases the duration of the transient 16 times and the fuel consumption 2 times. However not specifying them might lead to over- or undershooting the optimal point and the solution might thus not be fuel optimal if the goal is to produce a specific output power.
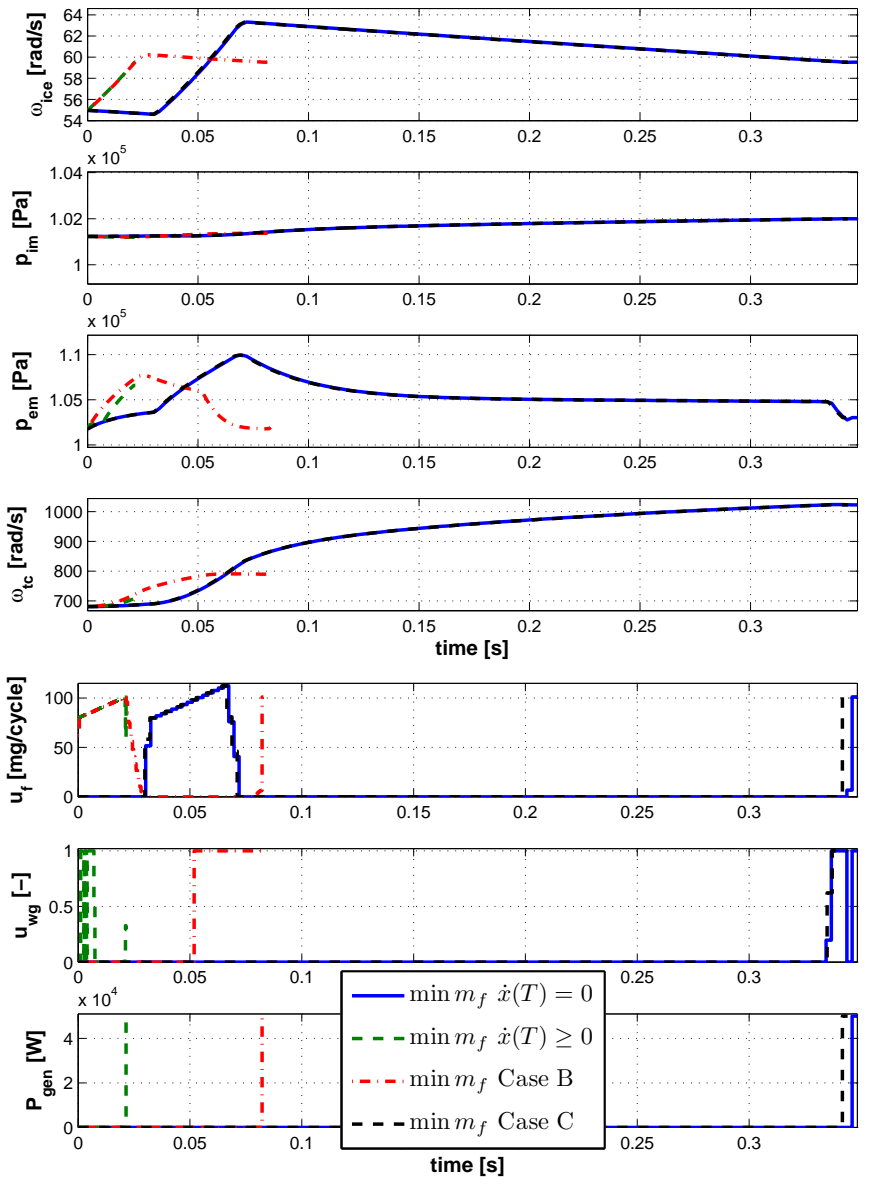

Fig. 13. Fuel optimal transient and how the solution changes with the end constraints, $P_{r e q}=50 \mathrm{~kW}$.

\section{CONCLUSION}

In this paper the characteristics of the fuel and time optimal control of a diesel-electric engine from idle to target power has been presented. The dominant effects have been studied through changing the end constraints of the optimization problem. It is shown that the optimal solutions are different for high and low requested powers. For high power transients the time and fuel optimal controls are very similar despite the criteria being different. The optimal control is to put as much energy as possible into the system, following the smoke-limiter and maximum torque line. The difference between the two criteria is which operating point they approach and also the fine tuning to get there. Whereas the time optimal control follows the smoke-limiter until the end, the fuel optimal control cuts off the fuel injection and ends near the operating point with highest efficiency obtainable without using the generator. This operating point requires more kinetic energy in the turbocharger which takes longer to build, but reduces the total amount of kinetic energy necessary to produce the requested power.

For low power transients the fuel and time optimal controls differ substantially. This is found to be related to the requirements that they have to end in a stationary operating point. How the turbocharger is controlled to a stationary point is the main difference. The fuel optimal control is to slowly build turbocharger speed and let the 
engine decelerate towards the stationary point, whereas the time optimal solution utilizes the generator to decrease the engine speed, mid-transient.

\section{ACKNOWLEDGEMENTS}

The support from BAE Systems and the funding from the Swedish Energy Agency FFI is gratefully acknowledged.

\section{REFERENCES}

Benz, M., Hehn, M., Onder, C.H., and Guzzella, L. (2011). Model-based actuator trajectories optimization for a diesel engine using a direct method. Journal of Engineering for Gas Turbines and Power, 133.

Eriksson, L. (2007). Modeling and control of turbocharged SI and DI engines. Oil \& Gas Science and Technology Rev. IFP, 62(4), 523-538.

Houska, B., Ferreau, H.J., and Diehl, M. (2011). ACADO toolkit - an open source framework for automatic control and dynamic optimization. Optimal Control Applications 8 Methods, 32(3), 298-312.

Kyrtatos, N.P., Tzanos, E.I., and Papadopoulos, C.I. (2003). Diesel engine control optmization for transient operation with lean/rich switches. Journal of Engineering for Gas Turbines and Power, 4(3), 219-232.

Nilsson, T., Fröberg, A., and Åslund, J. (2011). Optimized engine transients. In 7th IEEE Vehicle power and propulsion conference. Chicago, Illinois, USA.

Nilsson, T., Fröberg, A., and Åslund, J. (2012). Optimal operation of a turbocharged diesel engine during transients. In SAE Technical Paper 2012-01-0711.

Wahlström, J. and Eriksson, L. (2011). Modelling diesel engines with a variable-geometry turbocharger and exhaust gas recirculation by optimization of model parameters for capturing non-linear system dynamics. Proceedings of the Institution of Mechanical Engineers, Part D, Journal of Automobile Engineering, 225(7), 960-986.

Appendix A. MODEL DATA

Table A.1. Constants used

\begin{tabular}{cccc}
\hline \hline Symbol & Description & Value & Unit \\
\hline$p_{a m b}$ & Ambient pressure & $1.011 \cdot 10^{5}$ & $P a$ \\
$T_{a m b}$ & Ambient temperature & 298.46 & $\mathrm{~K}$ \\
$c_{p a}$ & Spec. heat capacity of air, constant pressure & 1011 & $\mathrm{~J} /(\mathrm{kg} \cdot \mathrm{K})$ \\
$c_{v a}$ & Spec. heat capacity of air, constant volume & 724 & $\mathrm{~J} /(\mathrm{kg} \cdot \mathrm{K})$ \\
$\gamma_{a}$ & Spec. heat capacity ratio of air & 1.3964 & - \\
$R_{a}$ & Gas constant, air & 287 & $\mathrm{~J} /(\mathrm{kg} \cdot \mathrm{K})$ \\
$c_{p e}$ & Spec. heat capacity of exhaust gas, constant pressure & 1332 & $\mathrm{~J} /(\mathrm{kg} \cdot \mathrm{K})$ \\
$\gamma_{e}$ & Spec. heat capacity ratio of exhaust gas & 1.2734 & - \\
$R_{e}$ & Gas constant, exhaust gas & 286 & $\mathrm{~J} /(\mathrm{kg} \cdot \mathrm{K})$ \\
$\gamma_{c y l}$ & Spec. heat capacity ratio of cylinder gas & 1.35004 & - \\
$T_{i m}$ & Temperature intake manifold & 300.6186 & $\mathrm{~K}$ \\
$p_{e s}$ & Pressure in exhaust system & $1.011 \cdot 10^{5}$ & $\mathrm{~Pa}$ \\
$(A / F)_{s}$ & Stoichiometric oxygen-fuel ratio & 14.57 & - \\
$q_{H V}$ & Heating value, diesel & $42.9 \cdot 10^{6}$ & $\mathrm{~J} / \mathrm{kg}$ \\
\hline
\end{tabular}

Table A.2. Parameters used

\begin{tabular}{cccc}
\hline \hline Symbol & Description & Value & Unit \\
\hline$n_{c y l}$ & Number of cylinders & 6 & - \\
$V_{D}$ & Engine displacement & 0.0127 & $\mathrm{~m}^{3}$ \\
$r_{c}$ & Compression ratio & 17.3 & - \\
$J_{g e n s e t}$ & Inertia of the engine-generator & 3.5 & $\mathrm{~kg} \cdot \mathrm{m}^{2}$ \\
$V_{i s}$ & Volume of intake system & 0.0218 & $\mathrm{~m}^{3}$ \\
$R_{c}$ & Compressor radius & 0.04 & $\mathrm{~m}$ \\
$\Psi_{\text {max }}$ & Max. compressor head parameter & 1.5927 & - \\
$\dot{m}_{c, \text { corr }, \text { max }}$ & Max. corrected compressor mass-flow & 0.5462 & $\mathrm{~kg} / \mathrm{s}$ \\
$\eta_{c}$ & Compressor efficiency & 0.5376 & - \\
$\eta_{v o l}$ & Volumetric efficiency & 0.8928 & - \\
$\eta_{i g, c h}$ & Combustion chamber efficiency & 0.6774 & - \\
$c_{f r 1}$ & Friction coefficient & $8.4100 \cdot 10^{-5}$ & - \\
$c_{f r 2}$ & Friction coefficient & $-5.6039 \cdot 10^{-3}$ & - \\
$c_{f r 3}$ & Friction coefficient & 0.4758 & - \\
$\eta_{s c}$ & Non-ideal Seliger cycle compensation & 1.0540 & - \\
$x_{c v}$ & Ratio of fuel burnt during constant volume & 0.4046 & - \\
$V_{\text {em }}$ & Volume of exhaust manifold & 0.0199 & $\mathrm{~m}^{3}$ \\
$J_{t c}$ & Turbocharger inertia & $1.9662 \cdot 10^{-4}$ & $\mathrm{~kg} \cdot \mathrm{m}^{2}$ \\
$w_{f r i c}$ & Turbocharger friction & $2.4358 \cdot 10^{-5}$ & $\mathrm{~kg} \cdot \mathrm{m}^{2} / \mathrm{rad}$ \\
$A_{t, e f f}$ & Effective turbine area & $9.8938 \cdot 10^{-4}$ & $\mathrm{~m}^{3}$ \\
$\eta_{t}$ & Turbine efficiency & 0.7278 & - \\
$c_{w g, 1}$ & Wastegate parameter & 0.6679 & - \\
$c_{w g, 2}$ & Wastegate parameter & 5.3039 & - \\
$A_{w g, e f f}$ & Effective wastegate area & $8.8357 \cdot 10^{-4}$ & $\mathrm{~m}^{3}$ \\
\hline & & &
\end{tabular}

